\title{
miR-203a-3p and MMP-2 protein are highly expressed in circulating tumor cells from patients with pancreatic carcinoma
}

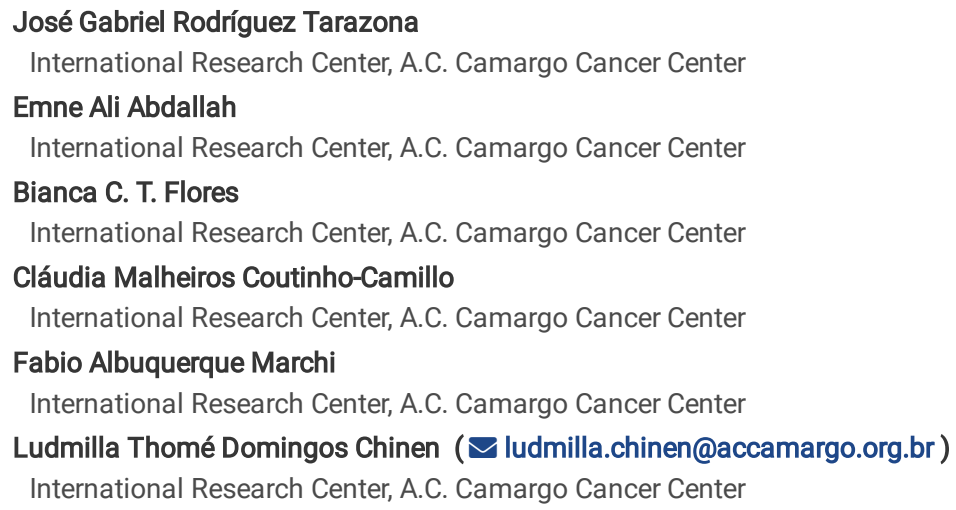

Keywords: Circulating Tumor Cells, Pancreatic Carcinoma, MMP2, miR-203a-3p, Deep Vein Thrombosis.

Posted Date: May 18th, 2021

DOI: https://doi.org/10.21203/rs.3.rs-523483/v1

License: () (7) This work is licensed under a Creative Commons Attribution 4.0 International License. Read Full License 


\section{Abstract}

Objectives: to explore the morphological, molecular and phenotypical characteristics of circulating tumor cells (CTCs) from blood of patients with pancreatic carcinoma, and to correlate the findings with response to treatment, progression-free survival, overall survival (OS) and deep vein thrombosis (DVT).

Methods: peripheral blood $(10 \mathrm{~mL})$ was analyzed before the beginning of treatment, and after 60 and 120 days. CTCs were detected by ISET ${ }^{\circledR}$ and characterized by immunocytochemistry. For miRNAs analysis, peripheral leukocytes from the same patients and healthy individuals (controls) were collected in parallel at baseline. The expression of miRNAs was evaluated (in pool) using TaqMan ${ }^{\text {TM }}$ Array Human MicroRNA Cards v2.0.

Results: there were included 9 patients. The proteins MMP2 and TGF 3 -RI were highly expressed (77.7\%) in CTCs at baseline; at the first follow-up, MMP2 was predominant (80\%) and at second follow-up, MMP2 and vimentin were predominant (50\%). Circulating tumor microemboli (CTM) were found in two patients and both presented DVT. The miR-203a-3p was highly expressed in CTCs. miR-203a-3p is involved in the stimulation of epithelial-to-mesenchymal transition (EMT) and related to worse OS in pancreatic cancer (TCGA data).

Conclusion: Due to the low number of patients and short follow-up, we did not observe a correlation between CTCs and response to treatment. However, there was a correlation between CTM and DVT as also miR-203a-3p was highly expressed in CTCs, corroborating the findings of EMT proteins. This study opens perspectives concerning the dynamic change in the pattern of proteins expressed along treatment and the use of miRNAs as new targets in pancreatic carcinoma.

\section{Introduction}

Pancreatic cancer is currently ranked as the 14th most common cancer and the 7th leading cause of cancer mortality in the world. There is a general trend of higher incidence rates in developed countries [1]. Although not among the top 10 cancers in Brazil, it is the eighth leading cause of death from cancer, due to diagnosis in locally advanced or metastatic stage of the disease [2]. The most common and also most aggressive histological subtype of pancreatic cancer is the pancreatic ductal adenocarcinoma (PDAC), which represents $85-90 \%$ of all pancreatic neoplasms [3].

Surgical resection continues as the only treatment modality with a potential for cure; however, only $15-20 \%$ of pancreatic cancer patients diagnosed with the disease are operable. However, the level of recurrences after surgery is still high, both local and systemic. Adjuvant treatment is used to improve survival prospects and involves chemotherapy, radiation and / or combined modalities, but there are still controversies regarding the treatment of choice [4].

CA19-9 has been applied as the "gold standard" for monitoring and diagnosing patients with pancreatic cancer [5], although its low positive predictive value, making it suitable only for monitoring response to treatment and as a marker of disease recurrence. The lack of a validated and specific biomarker for this disease remains a major challenge [6].

Circulating Tumor Cells (CTCs) leak from the tumor into the circulation and can potentially invade distant tissues to form evident metastases. While most CTCs are single cells, a small fraction travels as groups of cells [7]. A circulating tumor microemboli (CTM) is defined as a cluster or groups of CTCs containing three or more distinct nuclei [8]. CTM appear to have greater metastatic potential than individual CTCs in circulation [7].

A crucial step towards intravasation and survival in the bloodstream is to obtain plasticity and motility, which involves the epithelial-mesenchymal transition process (EMT) and both CTCs and CTMs can go through this process [9], that can be regulated by miRNAs.

MicroRNAs (miRNAs) form complex networks that regulate cell differentiation, development and homeostasis. The deregulation of its function is associated with an increasing number of human diseases, mainly cancer, being, therefore, prognostic markers or potential targets for new therapies against cancer [10]. Some miRNAs interact with the set of critical molecules involved in EMT engineering, modulating its expression and, consequently, its function [11].

Thus, this study aimed to evaluate the expression of proteins related to EMT and the expression of miRNAs in CTCs from patients with pancreatic carcinoma and to correlate these findings with clinical data, Deep Vein Thrombosis (DVT), progression-free survival (PFS) and overall survival (OS).

\section{Methods}

\subsection{Ethical Statement}

The protocol was approved by Research Ethics Committee of the A.C. Camargo Cancer Center (code 2388/17) in accordance with the ICH-GCP guidance.

\subsection{Study Design}

This was a prospective longitudinal single-center study performed by collecting whole blood from patients with pancreatic carcinoma, undergoing treatment with chemotherapy, immunotherapy or target therapy.

Blood samples $(10 \mathrm{~mL})$ were collected before the start of treatment, after 60 and 120 days, with imaging tests. As a negative control, blood from healthy individuals was used.

This project was submitted to the Research Ethics Committee of the A.C. Camargo Cancer Center (code 2388/17). The samples were collected by accepting and signing the Informed Consent Form. 
Inclusion criteria were: patients with histological diagnosis of locally advanced or metastatic pancreatic carcinoma; patients older than 18 years; patients submitted to the first line of treatment; metastatic disease confirmed by pathological and / or radiological evaluation; extent of the disease determined by clinical examination and imaging; disease measurable by the RECIST version 1.1 criteria (Response Evaluation Criteria in Solid Tumors). Patients submitted to previous cancer treatment were excluded.

\subsection{Isolation of CTCs and analysis of markers}

To separate the CTCs, the method of filtration by size through the ISET ${ }^{\circledR}$ device (Isolation by SizE of Tumor cells, Rarecells, France) was used. The patient's peripheral blood samples were collected in EDTA tubes and diluted to perform red blood cell lysis in 1:10 with ISET Buffer ${ }^{T M}$. After 10 minutes of homogenization, the samples were deposited in ISET Block ${ }^{T M}$, which contains a polycarbonate membrane with circular pores of $8 \mu \mathrm{m}$ in diameter. The equipment filters the samples by vacuum aspiration and then the membranes are washed with Phosphate Buffered Saline (PBS) 1X (pH: 7.3), removed from the ISET Block ${ }^{T M}$ and, when dried, stored at $-20^{\circ} \mathrm{C}$. Of the $10 \mathrm{ml}$ of blood analyzed, $6 \mathrm{ml}$ were destined for cytopathological analysis and $4 \mathrm{ml}$ for molecular analysis (submerging the membrane in later RNA and subsequent DNA and RNA extraction).

To characterize CTCs that were expressing the proteins evaluated in this study, we performed an immunocytochemistry (ICC) assay. Important proteins in the EMT were searched: anti-TGFB-R1 (Cusabio 1:100, code: CSB-PA061850), anti-Mesothelin (Sigma-Aldrich 1:50, code: SAB5500143), anti-Vimentin (Cusabio 1:100, code: CSB-PA025857LA01 HU), anti-MMP2 (Cusabio 1:100, code: CSB-PA06879A0Rb). For the ICC reaction positive controls, we used cell lines spiked in health blood samples and filtered through ISET ${ }^{\circledR}$. For anti-TGF $\beta-R 1$ antibody control we used the cell line A-549, for anti-Mesothelin antibody we used the Hela cell line, for anti-Vimentin we used the MCF7 cell line and for with anti-MMP2 we used the U87 cell line, according to The Human Protein Atlas

(http://www.proteinatlas.org/). As a negative control of ICC, we used the same cell line, omitting the primary antibody, to ensure that cross-reactivity was excluded. To confirm that the CTCs analyzed were not leukocytes, we used the anti-CD45 antibody (Sigma-Aldrich 1:100, code: HPA000440).

The ICC was performed with double marking, using the GBI LABS Golden Bridge International Kit with the desired markers. The ISET membrane spots were cut and placed in 24-well plates. Antigenic recovery was performed by adding $1 \mathrm{ml}$ of (DakoTM Target retrieval solution 1X) from each well by heating in a container microwave with distilled water for approximately 6 minutes with cooling intervals every 1 minute and 40 seconds. Each spot was hydrated with $160 \mu \mathrm{l}$ of Tris buffered saline $1 \mathrm{X}$ (TBS $1 \mathrm{X}, \mathrm{pH}: 7.3$ ) for 20 minutes. The cells were permeabilized with $160 \mu \mathrm{l}$ of $0.2 \%$ TBS + Triton X-100 for 5 minutes at room temperature. After a new wash with TBS, the membranes were incubated for 15 minutes, in the dark and at room temperature, with hydrogen peroxide, and washed again with TBS. Then the primary antibody was applied to the spots and incubated overnight. The membranes were washed again with TBS, incubated for 30 minutes in Polymer/HRP (Dako, Santa Clara, CA, USA), washed again and revealed by the DAB chromogen of the same Kit. Then, membranes were washed with TBS, followed by 2-hours incubation with the second primary antibody and a 30-minute incubation with the AP Polymer (GBI Labs). The second antibody was revealed by Permanent Red (GBI Labs). previously diluted according to the manufacturer's instructions for 10 minutes. Finally, the spot was washed with distilled water and stained with hematoxylin for 2 minutes, washed again with distilled water and adhered to the slides for reading under a light microscope using PBS.

The slides were examined under a white light microscope, BX61 - Olympus, (Tokyo, Japan) coupled to a high-resolution digital camera SC100 - Olympus, (Tokyo, Japan). CTCs were characterized according to the following criteria: nuclear size $\geq 16 \mu \mathrm{m}$, irregularity of the nuclear contour, presence of visible cytoplasm, high nucleus-cytoplasm ratio (>0.8). When any of the described criteria were missing, the cells were classified as atypical. The results were given in number of CTCs per $\mathrm{ml}$ of blood, according to statistical analysis performed by Krebs et al. (2012), counting CTCs in 4 membrane spots or more. After cytopathological analysis, the CTCs values were added and the mean was calculated. Thus, we had the CTCs calculations in $1 \mathrm{ml}$ of blood. In addition, the presence and absence of CTMs was included in the analysis.

\section{4. microRNA EXPRESSION ANALYSIS}

\subsubsection{RNA isolation}

RNA extraction was performed using the AllPrep DNA/RNA/miRNA Universal Kit (Qiagen, Hilden, Germany). Briefly, 4 membrane spots without formaldehyde were cut into small fragments (approximately $2 \mathrm{~mm}^{2}$ ) in $1.5 \mathrm{ml}$ microtubes and the cells were lysed using the RLT Plus buffer (Qiagen) and mixed for 1 minute. Subsequently, the steps were followed according to the manufacturer's instructions.

The RNA concentration was measured on the Nanodrop ${ }^{\text {TM }}$ ND-1000 spectrophotometer (Thermo Scientific) using $1.5 \mu$ of sample and checking the absorbance at $260 \mathrm{~nm}$.

\subsubsection{Real-time RT-PCR (qPCR)}

In order to verify the quality of the extracted RNA, a small nuclear RNA U6B (RNU6B) was amplified in all samples. The specific cDNA synthesis reaction was performed according to the procedures recommended in the TaqMan ${ }^{\circledR}$ MicroRNA Assays manual (Applied Biosystems). Only samples that presented a consistent amplification curve went on to analyze the microRNA profile.

The determination of miRNA expression profiles was performed using the TaqMan ${ }^{\mathrm{TM}}$ Array Human MicroRNA A Cards v2.0 methodology (containing 372 miRNAs and 7 controls) according to the MegaplexTM Pools for microRNA Expression Analysis kit (Applied Biosystems). The synthesis and pre-amplification of the cDNA was performed using 150ng of RNA from leukocytes from volunteers without neoplasia (pool of 5 samples), RNA from leukocytes from patients with pancreatic cancer (pool of 6 samples) and RNA from CTCs of patients with pancreatic cancer (pool of 9 samples). The amplification of the microRNAs was performed using the 7900HT Fast Real-Time PCR System (Applied Biosystems). 
The results were analyzed by the software RQ Manager 1.2 (Applied Biosystems). The level of expression of the miRNAs was quantified in relation to the expression of a reference miRNA and was normalized according to the calibrator sample (leukocyte sample pool from healthy volunteers). The miRNA used as a reference was miR-126, selected through the NormFinder tool (https://moma.dk/normfinder-software), which assesses which microRNA has the most stable expression in a set of samples. The relative quantification (Rq) was calculated using the $\Delta \triangle \mathrm{CT}$ method [13].

The miRNAs were selected according to the greatest difference in expression between the CTC and Leukocyte groups, assessed by fold-change $\geq 2$ for increased expression and $\leq-2$ for decreased expression. For the construction of the boxplot, the ggplot2 package available for the R program was used.

\subsubsection{Statistical analysis}

A descriptive analysis of each group (those that express EMT-related proteins versus those that do not) was performed in relation to the clinical-pathological variables. To assess differences and associations between groups, the Chi-Square method was used for categorical variables. To analyze PFS and OS I, the Kaplan-Meier method was used and the difference between the curves calculated by log-rank. All statistical analysis was performed using the SPSS program for Windows, version 15. The $p$ values were considered significant when $\leq 0.05$.

For the calculation of OS, we considered the time between the first sampling of the patient until his death and for PFS, we considered the time between the first sampling of the patient and the objective progression of the tumor. The baseline (first sample) of survival analyzes in this study was carried out from the date of the first collection of CTCs.

\section{Results}

\subsection{Clinical-pathological characteristics}

We collected sample from 10 patients with pancreatic adenocarcinoma before the surgical procedure (baseline) between 05/2018 and 09/2019. One patient was excluded from the study because pathological analysis confirmed that it was a neuroendocrine tumor. The first follow-up was carried out two months after the baseline collection in 5 patients, we lost 4 patients (death of one patient and loss of follow-up of 3 patients). The second follow-up (4 months after baseline collection) was performed in 8 patients.

Of the 9 patients included, 4 (44.44\%) were men and 5 (55.55\%) women, the median age was 59.7 years (42 - 82). Healthy donors ( $\mathrm{n}=7), 6$ women and 1 man, with a median age of 48 years, were also recruited as a control group for the analysis of the microRNA expression experiments.

Regarding the histological grade, $6 / 9$ patients had ductal adenocarcinoma (66.66\%), 2/9 patients (22.22\%) adenocarcinoma and in $1 / 9$ (11.11\%) the tumor was classified as carcinoma.

Of the 9 patients included, 3 (33.33\%) progressed and 6 patients remained at the same stage of the disease at the time of the last follow-up. Of the three patients that progressed, two had non-metastatic disease and one metastatic disease.

Patients who had experienced progression had a greater distribution of CTCs at the baseline $(p=0.54)$. The differences in the levels of CTCs throughout the treatment are shown in Figure 1.

Regarding the pathological staging of the patients included in this study, 4 started the study in stage IV (44.44\%), two in stage III (22.22\%), two in stage IB (22.22\%) and one patient in stage IIB (11.11\%). Regarding metastases (pM), 5 patients (55.55\%) were M0 and 4 (44.44\%) were M1.

Concerning the therapeutic strategy established for the patients in this study, it was found in the medical records that 4 patients (44.44\%) started palliative treatment, three patients (33.33\%) neoadjuvant treatment and two patients (22.22\%) curative treatment. The other clinical and pathological characteristics of the patients are described in Table 1.

Table 1 - Clinical and pathological characteristics of the study patients ( $n=9)$. TNM staging according to AJCC. 


\begin{tabular}{|c|c|c|}
\hline Variables (n) & No & $\%$ \\
\hline Total number of patients & 9 & 100 \\
\hline \multicolumn{3}{|l|}{ Age at study entry, in years (9) } \\
\hline Average & 57 & \\
\hline Median & 59.7 & \\
\hline Variation & $42-82$ & \\
\hline \multicolumn{3}{|l|}{ Gender (9) } \\
\hline Male & 4 & 44,44 \\
\hline Female & 5 & 55.55 \\
\hline \multicolumn{3}{|l|}{ Histological grade (9) } \\
\hline Ductal adenocarcinoma & 6 & 66.66 \\
\hline Adenocarcinoma & 2 & 22.22 \\
\hline Carcinoma & 1 & 11.11 \\
\hline \multicolumn{3}{|l|}{ Primary site diagnosis (9) } \\
\hline Malignant neoplasm of pancreas & 9 & 100 \\
\hline \multicolumn{3}{|l|}{ Metastases in diagnosis (9) } \\
\hline Yes & 4 & 44.44 \\
\hline No & 5 & 55.55 \\
\hline \multicolumn{3}{|l|}{ Progression (9) } \\
\hline Yes & 3 & 33.33 \\
\hline No & 6 & 66.66 \\
\hline \multicolumn{3}{|l|}{ Thrombosis (9) } \\
\hline Deep Venous Thrombosis & 2 & 22.22 \\
\hline Data not available & 2 & 22.22 \\
\hline Without Deep Venous Thrombosis & 5 & 55.55 \\
\hline \multicolumn{3}{|l|}{ Tumor size (pT) (9) Baseline } \\
\hline T2 & 2 & 22.22 \\
\hline T3 & 1 & 11.11 \\
\hline $\mathrm{T} 4$ & 6 & 66.66 \\
\hline \multicolumn{3}{|c|}{ Lymph node involvement (pN) (9) Baseline } \\
\hline N0 & 4 & 44.44 \\
\hline N1 & 5 & 55.55 \\
\hline \multicolumn{3}{|l|}{ Metastases (pM) (9) Baseline } \\
\hline M0 & 5 & 55.55 \\
\hline M1 & 4 & 44.44 \\
\hline \multicolumn{3}{|l|}{ Pathological staging (9) } \\
\hline IB & 2 & 22.22 \\
\hline III & 2 & 22.22 \\
\hline IIB & 1 & 11.11 \\
\hline IV & 4 & 44.44 \\
\hline \multicolumn{3}{|l|}{ Therapeutic Strategy (9) } \\
\hline Neoadjuvance & 3 & 33.33 \\
\hline Palliative & 4 & 44.44 \\
\hline Curative & 2 & 22.22 \\
\hline
\end{tabular}

Table 2 - Data of the study biomarkers, CTC detection rate, markers in CTCs at all times of the study $(n=9)$. 


\begin{tabular}{|c|c|c|}
\hline Variables (n) & $\mathrm{N}^{\mathbf{0}}$ & $\%$ \\
\hline \multicolumn{3}{|l|}{ Biomarkers } \\
\hline Median level of CA 19-9 (UI / mL) Baseline & $337.9(3.1-41544)$ & \\
\hline Average level of CA 19-9 (UI / mL) Baseline & $7841.7(3.1-41544)$ & \\
\hline \multicolumn{3}{|l|}{ Median No. of CTCs / mL } \\
\hline 1st collection (evaluated on 9/9) & $2(0-19.5)$ & \\
\hline 2nd collection (evaluated on $5 / 9$ ) & $4.5(2-20)$ & \\
\hline 3rd collection (evaluated on $9 / 9$ ) & $2.75(0-11.5)$ & \\
\hline \multicolumn{3}{|l|}{ Patients with the presence of CTCs } \\
\hline 1st collection (evaluated on $9 / 9$ ) & 8 & 88.88 \\
\hline 2nd collection (evaluated on $5 / 9$ ) & 5 & 55.55 \\
\hline 3rd collection (evaluated on $9 / 9$ ) & 7 & 77.77 \\
\hline Total Collections (22) & 20 & 90.90 \\
\hline \multicolumn{3}{|l|}{ Patients with MMP2 positive Circulating Tumor Cells } \\
\hline 1st collection (evaluated 9) & 7 & 77.77 \\
\hline 2nd collection (evaluated 5) & 4 & 80 \\
\hline 3rd collection (evaluated 8) & 4 & 50 \\
\hline \multicolumn{3}{|c|}{ Patients with VIMENTIN positive Circulating Tumor Cells } \\
\hline 1st collection (evaluated 9) & 3 & 33.33 \\
\hline 2nd collection (evaluated in 5) & 3 & 60 \\
\hline 3rd collection (evaluated in 8) & 2 & 25 \\
\hline \multicolumn{3}{|c|}{ Patients with TGFB-R1 positive Circulating Tumor Cells } \\
\hline 1st collection (evaluated 9) & 4 & 44.44 \\
\hline 2nd collection (evaluated 5) & 3 & 60 \\
\hline 3rd collection (evaluated 8) & 1 & 12.5 \\
\hline \multicolumn{3}{|l|}{ Patients with Circulating Tumor Microemboli } \\
\hline 1st collection (evaluated 9) & 1 & 11.11 \\
\hline 2nd collection (evaluated 5) & 0 & 0 \\
\hline 3rd collection (evaluated 8) & 1 & 12.5 \\
\hline
\end{tabular}

CA 19-9, carbohydrate antigen 19-9

\subsection{Protein Expression in CTCs}

We evaluated the expression of proteins involved in the EMT process by immunocytochemistry in the CTCs of 9 patients in the first collection, 5 in the second collection and 8 patients in the third collection.

We analyzed the protein expression of CTCs separately, relating each marker to each collection and what we could observe was the expression of MMP2 in $77.77 \%$ of the cases of the first collection (C1). In fact, patients with MMP2 expression in CTCs at C1 had a higher distribution of CTC levels, but without statistical significance $(p=0.33)$.

TGF $\beta$-R1 was found to be expressed in $44.44 \%$ of cases. Patients with TGF $\beta$-R1 expression in CTCs at C1 showed a higher distribution of CTCs levels, without statistical significance $(p=0.09)$ as also Vimentin.

There was no statistically significant difference in the number of cases with the presence of proteins or correlation with the presence of distant metastasis, or with disease progression at any time analyzed. Protein expressions in CTCs are described in Table 2 and the relationship of the markers with clinical evolution in Table 3.

Table 3 - Clinical and protein expression characteristics of the patients involved in the study. 


\begin{tabular}{|c|c|c|c|c|c|c|c|c|c|c|c|c|c|c|c|c|c|c|}
\hline Pte & $\mathrm{Gn}$ & Phase & $\mathrm{T}$ & $\mathbf{N}$ & $\mathbf{M}$ & $\begin{array}{c}\text { Histological } \\
\text { type }\end{array}$ & $\begin{array}{l}\mathrm{M} \\
\mathrm{Dx}\end{array}$ & M Site & $\begin{array}{l}\text { 1st Coll. } \\
\text { CTC/ml }\end{array}$ & $\begin{array}{c}\text { Protein } \\
\text { Expression }\end{array}$ & $\begin{array}{l}\text { 2nd Coll. } \\
\text { CTC/ml }\end{array}$ & $\begin{array}{c}\text { Protein } \\
\text { Expression }\end{array}$ & $\begin{array}{l}\text { 3rd Coll. } \\
\text { CTC/ml }\end{array}$ & $\begin{array}{c}\text { Protein } \\
\text { Expression }\end{array}$ & CTM & $\begin{array}{l}\text { CA } 19-9 \\
\text { to } \mathrm{Dx}\end{array}$ & Prog & Treatment \\
\hline 1 & $\mathrm{~F}$ & III & 4 & 0 & 0 & Carcinoma & No & 2 & $\begin{array}{l}\text { VIM, } \\
\text { TGFB }\end{array}$ & 7 & $\begin{array}{l}\text { MESOTH, } \\
\text { VIM, } \\
\text { TGFB }\end{array}$ & 3.5 & $\begin{array}{c}\text { MMP2, } \\
\text { VIM, } \\
\text { TGFB }\end{array}$ & Yes & 211 & No & Neoadjuvant & DVT MSD \\
\hline 2 & M & III & 4 & 0 & 0 & $\begin{array}{c}\text { Ductal } \\
\text { adenocarcinoma }\end{array}$ & No & 2 & MMP2 & 4.5 & $\begin{array}{l}\text { MMP2, } \\
\text { VIM, } \\
\text { TGFB }\end{array}$ & 1 & MMP2 & No & 337.9 & No & Neoadjuvant & No data \\
\hline 3 & $\mathrm{~F}$ & IB & 2 & 0 & 0 & $\begin{array}{c}\text { Ductal } \\
\text { adenocarcinoma }\end{array}$ & No & 1 & $\begin{array}{c}\text { MMP2, } \\
\text { TGFB }\end{array}$ & 2 & MMP2 & 0 & ------------ & No & 26.5 & Yes & Neoadjuvant & No data \\
\hline 6 & $\mathrm{~F}$ & IB & 2 & 0 & 0 & $\begin{array}{c}\text { Ductal } \\
\text { adenocarcinoma }\end{array}$ & No & 19.5 & $\begin{array}{l}\text { MMP2, } \\
\text { MESOTH, } \\
\text { VIM, } \\
\text { TGFB }\end{array}$ & $\begin{array}{l}\text { Collection } \\
\text { loss }\end{array}$ & ------------- & 2.5 & $\begin{array}{l}\text { Negative } \\
\text { CTCs }\end{array}$ & No & 39 & No & Curative & Without DV \\
\hline 10 & M & IIB & 3 & 1 & 0 & $\begin{array}{c}\text { Ductal } \\
\text { adenocarcinoma }\end{array}$ & No & 7 & MMP2 & $\begin{array}{c}\text { Patient } \\
\text { death }\end{array}$ & ------------ & $\begin{array}{l}\text { Patient } \\
\text { Death }\end{array}$ & ------------ & No & 388.5 & Yes & Curative & Without DV \\
\hline 5 & M & IV & 4 & 1 & 1 & Adenocarcinoma & Yes & Liver & 6 & $\begin{array}{l}\text { MMP2, } \\
\text { VIM, } \\
\text { TGFB-RI }\end{array}$ & $\begin{array}{l}\text { Collection } \\
\text { loss }\end{array}$ & ------------ & 3 & $\begin{array}{l}\text { Negative } \\
\text { CTCs }\end{array}$ & No & 3,1 & Yes & Palliative \\
\hline 7 & M & IV & 4 & 1 & 1 & Adenocarcinoma & Yes & $\begin{array}{c}\text { Liver, } \\
\text { Peritoneum }\end{array}$ & 1.5 & $\begin{array}{l}\text { MMP2, } \\
\text { MESOTH }\end{array}$ & $\begin{array}{l}\text { Collection } \\
\text { loss }\end{array}$ & ------------ & 1 & MMP2 & No & 41544 & No & Palliative \\
\hline 8 & $\mathrm{~F}$ & IV & 4 & 1 & 1 & $\begin{array}{c}\text { Ductal } \\
\text { adenocarcinoma }\end{array}$ & Yes & Liver & 0.5 & MMP2 & 4 & MMP2 & 3 & VIM & Yes & 6700 & No & Palliative \\
\hline 9 & $\mathrm{~F}$ & IV & 4 & 1 & 1 & $\begin{array}{c}\text { Ductal } \\
\text { adenocarcinoma }\end{array}$ & Yes & $\begin{array}{l}\text { Liver, } \\
\text { Lymph } \\
\text { Nodes }\end{array}$ & 0 & ------------ & 20 & $\begin{array}{c}\text { MMP2, } \\
\text { VIM, } \\
\text { TGFB }\end{array}$ & 11.5 & MMP2 & No & 21325.9 & No & Palliative \\
\hline
\end{tabular}

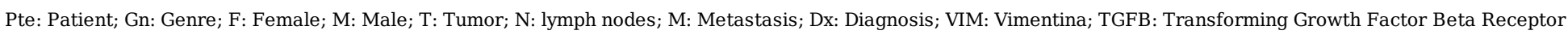

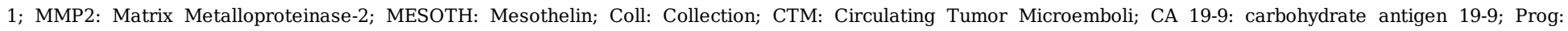

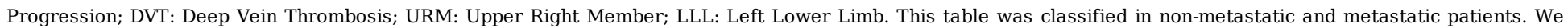
found that patients with circulating tumor microemboli had deep venous tumors.

\subsection{Expression of microRNAs}

Table 4 shows the 14 best miRNAs selected in the study, 13 with less expression in CTCs compared to the same patients leukocytes and one with higher expression in CTCs after the same comparison to patients leukocytes.

Table 4 - Comparison between miRNAs differentially expressed in CTCs and in primary tumors obtained in TCGA. 14 miRNAs agreed with the expression between CTCs and tumor (13 downexpressed and 1 overexpressed).

\begin{tabular}{l|llll}
\hline miRNAs (CTCs) & FC & Pval & Study & Status \\
\hline miR-132-5p* & $-1,72$ & $1,78 \mathrm{E}-02$ & $-38,64$ & Low \\
miR-143-5p* & $-1,80$ & $4,44 \mathrm{E}-02$ & $-26,28$ & Low \\
miR-197-3p* & $-1,88$ & $7,41 \mathrm{E}-04$ & $-21,87$ & Low \\
miR-142-3p* & $-5,26$ & $5,08 \mathrm{E}-05$ & $-8,66$ & Low \\
miR-223-3p* & $-3,93$ & $2,90 \mathrm{E}-03$ & $-7,29$ & Low \\
miR-223-5p* & $-2,70$ & $3,06 \mathrm{E}-03$ & $-7,29$ & Low \\
miR-142-5p* & $-3,48$ & $1,50 \mathrm{E}-03$ & $-6,93$ & Low \\
miR-145-5p* & $-2,23$ & $3,56 \mathrm{E}-03$ & $-6,67$ & Low \\
miR-145-3p* & $-1,75$ & $1,81 \mathrm{E}-02$ & $-6,67$ & Low \\
miR-22-5p* & $-2,94$ & $9,06 \mathrm{E}-06$ & $-6,06$ & Low \\
miR-345-5p* & $-2,11$ & $2,62 \mathrm{E}-03$ & $-4,03$ & Low \\
miR-340-3p* & $-2,22$ & $2,18 \mathrm{E}-04$ & $-3,94$ & Low \\
miR-340-5p* & $-1,74$ & $3,46 \mathrm{E}-02$ & $-3,94$ & Low \\
miR-150-5p & $-3,73$ & $2,26 \mathrm{E}-02$ & $-2,86$ & Low \\
miR-150-3p & $-2,56$ & $2,19 \mathrm{E}-03$ & $-2,86$ & Low \\
miR-191-5p & $-2,46$ & $1,28 \mathrm{E}-05$ & $-2,72$ & Low \\
miR-342-3p & $-2,80$ & $3,64 \mathrm{E}-04$ & $-2,66$ & Low \\
miR-18a-5p & $-2,07$ & $3,22 \mathrm{E}-03$ & $-2,63$ & Low \\
miR-18a-3p & $-1,46$ & $1,47 \mathrm{E}-02$ & $-2,63$ & Low \\
miR-590-5p & $-1,88$ & $3,81 \mathrm{E}-03$ & $-2,54$ & Low \\
miR-362-3p & $-1,83$ & $4,77 \mathrm{E}-03$ & $-2,26$ & Low \\
miR-324-5p & $-1,92$ & $9,09 \mathrm{E}-03$ & $-2,11$ & Low \\
miR-28-3p & $-1,59$ & $4,86 \mathrm{E}-02$ & $-2,05$ & Low \\
miR-28-5p & $-1,43$ & $2,62 \mathrm{E}-02$ & $-2,05$ & Low \\
miR-203a-3p* & 3,90 & $3,53 \mathrm{E}-02$ & 35,80 & High \\
\hline
\end{tabular}

T: Tumor; NT: Normal Tissue; FC: Fold-Change; Pval: P-value. The asterisk $\left(^{*}\right)$ indicates the miRNAs that showed the expression profile with the same direction of the miRNAs identified in this study. 
182 pancreatic cancer samples obtained from TCGA (The Cancer Genome Atlas) were selected for the evaluation of miRNAs differentially expressed between neoplastic and non-neoplastic samples. Only samples from patients with early pathological stage (I and II) were considered, resulting in 50 samples. We considered as significant miRNAs with p-value $<0.05$ and fold-change $\geq 2$ and $\leq-2$. The 93 selected targets were compared with those obtained in this study, resulting in 25 candidates. It was observed that miR-203a-3p was associated with poor OS in patients with early diagnosis of the disease. It can be verified that the increased expression of the miR-203a-3p is related to poor OS in patients with early-stage pancreatic cancer (Figure 3). This analysis was conducted with the survminer package (https://github.com/kassambara/survminer/) from 167 early-stage pancreatic cancer samples that presented available information for the survival curve.

\section{Discussion}

In our study was possible to find CTCs in all 9 pancreatic cancer patients included. We found MMP-2 highly expressed in these cells, as also a correlation between the presence of CTM and DTV, which opens perspectives in the monitoring of patients with pancreatic cancer, so prone to DTV. As we expected, we found an EMT-related microRNA highly expressed in these patients' CTCs, miR-203a-3p. So, despite the little genetic material, due to the low number of CTCs isolated from patients, we obtained important information, which can serve as new therapeutic targets. We believe that the model of the sample pool of our experiment allows to dimension targets that in only a patient could not be found, due to the diversity and heterogeneity of the CTCs.

Matrix metalloproteinases (MMP) are a family of proteolytic enzymes that degrade multiple components of the extracellular matrix, including those in the basement membrane of the vessels. They are involved in tumor invasion, neoangiogenesis and metastasis [14]. MMP2 (gelatinase A) breaks down type IV collagen, gelatin, elastin and proteoglycans. It is regulated in many types of cancer, such as glioblastomas, melanomas, breast cancer and colon cancer, promoting invasion and metastasis. Inhibition of MMP2 has been shown to cause radiosensitization, a decrease in tumor growth and invasiveness, identifying this enzyme as an interesting target for the development of diagnostic and therapeutic approaches [15]

[16] studied the expression of MMP2 in circulating prostate cells (CPCs), disseminated tumor cells (DTCs) and micrometastases (mM) in the bone marrow of men with prostate cancer by immunocytochemistry. In 185 patients with non-metastatic cancer, CPCs were detected in $62.7 \%$, DTCs in $62.2 \%$ and $\mathrm{mM}$ in $71.4 \%$. In 30 patients with metastatic cancer, $100 \%$ of CPCs, DTCs and mM were detected. In all CPCs, DTCs and mM, the expression of MMP2 was positively associated with an increase in the Gleason score. The expression of MMP2 in CPCs and DTCs showed agreement. Our findings, although in pancreatic cancer, demonstrated that MMP2 expression was the highest of all study proteins in all collections, being the highest expression found in the second collection, in $80 \%$ of patients.

In a study by [17] peripheral and portal blood samples were obtained from 50 patients with PDAC before surgical resection and filtered using ISET. CTCs were identified by immunofluorescence for cytokeratin and vimentin positivity. Cytokeratin was found to be expressed in $78 \%$ of patients and vimentin in $67 \%$. The detection of CTCs expressing both vimentin and cytokeratin was predictive of recurrence $(P=0.01)$. In our study, vimentin was not highly expressed in the first collection, although its expression in the second collection increased, which may lead to the hypothesis that it is a mechanism of resistance to chemotherapy after the start of chemotherapy.

In a previous study by our group, [18] studied TGFß-RI expression in patients with pancreatic ductal adenocarcinoma and 16 patients were tested for TGFß-RI, 4 showing positive marking ( $25 \%$ of patients). There was no statistically significant difference in SLP between patients who showed positive marking for TGFß-RI compared to those who did not. However, when TGFß-RI and MMP-2 were evaluated together, those patients who presented either or both (mesenchymal markers) on CTCs, progressed more quickly than those without any mesenchymal markers (2.84 vs. 5.43 months), although with no statistically significant difference $(p=0.14)$. Our study allowed us to see the kinetics of this protein in the three collections, noticing an increase in the second moment, presenting in $60 \%$ of the patients and with an important drop in expression in the third moment of the collections, which may expose that the mesenchymal phenotype is more exhibited after the start of chemotherapy, it can, maybe, represent a tumor resistance mechanism.

Vimentin, a major constituent of the intermediate filament protein family, is ubiquitous in normal mesenchymal cells and is known to maintain cell integrity and provide resistance against stress. Increased vimentin expression has been reported in various epithelial cancers (prostate, breast, melanoma, lung, gastrointestinal and CNS tumors), correlating with increased tumor growth, invasion and poor prognosis. However, the role of vimentin in cancer progression remains unclear, despite being widely used as a marker for EMT[19]. Higher expression of vimentin in pancreatic cancer cells may imply a higher state of malignancy [20].

A recent study analyzed whether vimentin on the cell surface could be a biomarker to isolate CTCs in pancreatic ductal adenocarcinoma (PDAC) and observed that this protein was highly expressed in pancreatic tumor cells with mesenchymal phenotype. Positive CTCs for vimentin (CTCvim) were detected in 76/100 patients with PDAC, using a microfluidic assay. CTCvim counts correlated with changes in tumor burden for patients undergoing resection. Significantly reduced CTC counts were seen after chemotherapy in subjects who responded to treatment. Higher CTC counts in the preoperative period correlated with lower recurrence-free survival. Together, vimentin and CTCs, can be trusted biomarkers in PDAC [21].

Corroborating our findings with miR-203a-3p, [22] performed small RNA sequences of an epithelial breast cell line (D492) and its mesenchymal derivative (D492M) grown in a three-dimensional microenvironment. Among the most regulated miRNAs in D492M was miR-203a, a miRNA that plays an important role in epithelial differentiation. The increased expression of miR-203a was seen in D492. When miR-203a was overexpressed in D492M, a partial reversal towards the epithelial phenotype was observed. The analysis of gene expression of D492M and D492MmiR-203a revealed peroxidasin, involved in the production of collagen IV, as the most significantly regulated gene in D492MmiR-203a. Overexpression of miR-203a in D492M induced partial TME and reduced peroxidasin expression. In addition, the authors demonstrated that miR-203a is a new peroxidasin repressor. The MiR-203-peroxidasin axis can be an important regulator 
of EMT/MET and remodeling of the basement membrane. In CTCs, this microRNA may be involved in these mechanisms, additional studies are needed to better understand this pathway and its role in CTCs from patients with pancreatic cancer.

Chen et al. (2019) aimed to provide a new therapeutic target (LINC00342) for NSCLC therapy. Target expression was detected by real-time PCR (qRT-PCR). Cell migration and invasion were measured by transwell assay. The DIANA tools of the online software were used to predict the connection of the LINC00342 and miR-203a-3p by luciferase. LINC00342 expression was increased in tissues and NSCLC cells compared to normal tissues and cells. The elimination of LINC00342 suppressed cell proliferation, colony formation, migration and invasion. The study suggested that LINC00342 contributes to the growth and metastasis of NSCLC cells through the competitive targeting of miR-203a-3p.

Thus, despite the super-restricted cohort, our data open perspectives for new ways of evaluating CTCs, not only analyzing them under the cytopathological aspect, but also at the microRNAs level. This associated information, in a well-designed study, may be useful in the clinical and therapeutic management of patients with pancreatic adenocarcinoma.

\section{Declarations}

Acknowledgments: National Council for Scientific and Technological Development (CNPq), for the Student-Agreement and Graduate Program - PEC-PG Master's - process 190144 / 2017-3. This project was financed by the Public Ministry: TAC-MP-PAJ nº 00968.2012.10.000/0.

Funding. This project was financed by the Public Ministry of Labor: TAC-MP-PAJ nº 00968.2012.10.000/0 and for the National Council for Scientific and Technological Development (CNPq), for the Student-Agreement and Graduate Program - PEC-PG - Master's - process 190144/2017-3

Conflicts of interest/Competing interests. The authors have no conflicts of interest/competing interests to declare.

Ethics approval: $2388 / 17$

Data availability. Not Applicable.

Code availability. Not Applicable.

Authors' contributions. All authors contributed to the study conception and design. Conceptualization: Ludmilla Thomé Domingos Chinen; Methodology: Ludmilla Thomé Domingos Chinen, Bianca C. T. Flores, Cláudia Camillo, Fabio Albuquerque; Formal analysis and investigation: Emne Abdallah, Ludmilla Thomé Domingos Chinen, José Rodríguez; Writing - original draft preparation: Ludmilla Thomé Domingos Chinen, José Rodríguez; Writing - review and editing: Ludmilla Thomé Domingos Chinen, José Rodríguez, Emne Abdallah; Funding acquisition: Ludmilla Thomé Domingos Chinen, Cláudia Camillo; Resources: Ludmilla Thomé Domingos Chinen, Cláudia Camillo; Supervision: Ludmilla Thomé Domingos Chinen, Cláudia Camillo, Fabio Albuquerque.

\section{References}

[1] McGuigan A, Kelly P, Turkington RC, Jones C, Coleman HG, McCain RS. Pancreatic cancer: A review of clinical diagnosis, epidemiology, treatment and outcomes. World J Gastroenterol 2018;24:4846-61. https://doi.org/10.3748/wjg.v24.i43.4846.

[2] Soldan M. Pancreatic cancer screening. Rev Colégio Bras Cir 2017;44:109-11. https://doi.org/10.1590/0100-69912017002015.

[3] Åkerberg D, Ansari D, Andersson R, Tingstedt B. The Effects of Surgical Exploration on Survival of Unresectable Pancreatic Carcinoma: A Retrospective Case-Control Study. J Biomed Sci Eng 2017;10:1-9. https://doi.org/10.4236/jbise.2017.101001.

[4] Blaszak M, El-Masri M, Hirmiz K, Mathews J, Omar A, Elfiki T, et al. Survival of patients with pancreatic cancer treated with varied modalities: A singlecentre study. Mol Clin Oncol 2017;6:583-8. https://doi.org/10.3892/mco.2017.1179.

[5] Grützmann R. Epidemiology, Treatment, and Outcome of Pancreatic Cancer. Mol. Diagn. Treat. Pancreat. Cancer, Elsevier; 2014, p. 3-9. https://doi.org/10.1016/B978-0-12-408103-1.00001-7.

[6] Zhou B, Xu J-W, Cheng Y-G, Gao J-Y, Hu S-Y, Wang L, et al. Early detection of pancreatic cancer: Where are we now and where are we going?: Early detection of pancreatic cancer. Int J Cancer 2017;141:231-41. https://doi.org/10.1002/ijc.30670.

[7] Aceto N, Toner M, Maheswaran S, Haber DA. En Route to Metastasis: Circulating Tumor Cell Clusters and Epithelial-to-Mesenchymal Transition. Trends Cancer 2015;1:44-52. https://doi.org/10.1016/j.trecan.2015.07.006.

[8] Hou J-M, Krebs MG, Lancashire L, Sloane R, Backen A, Swain RK, et al. Clinical Significance and Molecular Characteristics of Circulating Tumor Cells and Circulating Tumor Microemboli in Patients With Small-Cell Lung Cancer. J Clin Oncol 2012;30:525-32. https://doi.org/10.1200/JCO.2010.33.3716.

[9] Mader S, Pantel K. Liquid Biopsy: Current Status and Future Perspectives. Oncol Res Treat 2017;40:404-8. https://doi.org/10.1159/000478018.

[10] Gebert LFR, MacRae IJ. Regulation of microRNA function in animals. Nat Rev Mol Cell Biol 2019;20:21-37. https://doi.org/10.1038/s41580-0180045-7.

[11] Abba M, Patil N, Leupold J, Allgayer H. MicroRNA Regulation of Epithelial to Mesenchymal Transition. J Clin Med 2016;5:8.

https://doi.org/10.3390/jcm5010008. 
[12] Krebs MG, Hou J-M, Sloane R, Lancashire L, Priest L, Nonaka D, et al. Analysis of Circulating Tumor Cells in Patients with Non-small Cell Lung Cancer Using Epithelial Marker-Dependent and -Independent Approaches. J Thorac Oncol 2012;7:306-15. https://doi.org/10.1097/JTO.0b013e31823c5c16.

[13] Livak KJ, Schmittgen TD. Analysis of Relative Gene Expression Data Using Real-Time Quantitative PCR and the 2- $\triangle \Delta C T$ Method. Methods 2001;25:402-8. https://doi.org/10.1006/meth.2001.1262.

[14] Winer A, Adams S, Mignatti P. Matrix Metalloproteinase Inhibitors in Cancer Therapy: Turning Past Failures Into Future Successes. Mol Cancer Ther 2018;17:1147-55. https://doi.org/10.1158/1535-7163.MCT-17-0646.

[15] Panth KM, van den Beucken T, Biemans R, Lieuwes NG, Weber M, Losen M, et al. In vivo optical imaging of MMP2 immuno protein antibody: tumor uptake is associated with MMP2 activity. Sci Rep 2016;6:22198. https://doi.org/10.1038/srep22198.

[16] Murray NP, Reyes E, Tapia P, Badinez L, Orellana N, Fuentealba C, et al. Redefining micrometastasis in prostate cancer - a comparison of circulating prostate cells, bone marrow disseminated tumor cells and micrometastasis: Implications in determining local or systemic treatment for biochemical failure after radical prostatectomy. Int J Mol Med 2012;30:896-904. https://doi.org/10.3892/ijmm.2012.1071.

[17] Poruk KE, Valero V, Saunders T, Blackford AL, Griffin JF, Poling J, et al. Circulating Tumor Cell Phenotype Predicts Recurrence and Survival in Pancreatic Adenocarcinoma. Ann Surg 2016;264:1073-81. https://doi.org/10.1097/SLA.0000000000001600.

[18] Gasparini-Junior JL, Fanelli MF, Abdallah EA, Chinen LTD. EVALUATING MMP-2 AND TGFß-RI EXPRESSION IN CIRCULATING TUMOR CELLS OF PANCREATIC CANCER PATIENTS AND THEIR CORRELATION WITH CLINICAL EVOLUTION. ABCD Arq Bras Cir Dig São Paulo $2019 ; 32$.

https://doi.org/10.1590/0102-672020190001e1433.

[19] Sharma P, Alsharif S, Fallatah A, Chung BM. Intermediate Filaments as Effectors of Cancer Development and Metastasis: A Focus on Keratins, Vimentin, and Nestin. Cells 2019;8:497. https://doi.org/10.3390/cells8050497.

[20] Zhou Y-F, Xu W, Wang X, Sun J-S, Xiang J-J, Li Z-S, et al. Negative methylation status of vimentin predicts improved prognosis in pancreatic carcinoma. World J Gastroenterol 2014;20:13172-7. https://doi.org/10.3748/wjg.v20.i36.13172.

[21] Wei T, Zhang X, Zhang Q, Yang J, Chen Q, Wang J, et al. Vimentin-positive circulating tumor cells as a biomarker for diagnosis and treatment monitoring in patients with pancreatic cancer. Cancer Lett 2019;452:237-43. https://doi.org/10.1016/j.canlet.2019.03.009.

[22] Briem E, Budkova Z, Sigurdardottir AK, Hilmarsdottir B, Kricker J, Timp W, et al. MiR-203a is differentially expressed during branching morphogenesis and EMT in breast progenitor cells and is a repressor of peroxidasin. Mech Dev 2019;155:34-47. https://doi.org/10.1016/j.mod.2018.11.002.

[23] Chen Q-F, Kong J-L, Zou S-C, Gao H, Wang F, Qin S-M, et al. LncRNA LINC00342 regulated cell growth and metastasis in non-small cell lung cancer via targeting miR-203a-3p. Eur Rev Med Pharmacol Sci 2019;23:7408-18. https://doi.org/10.26355/eurrev_201909_18849.

\section{Figures}

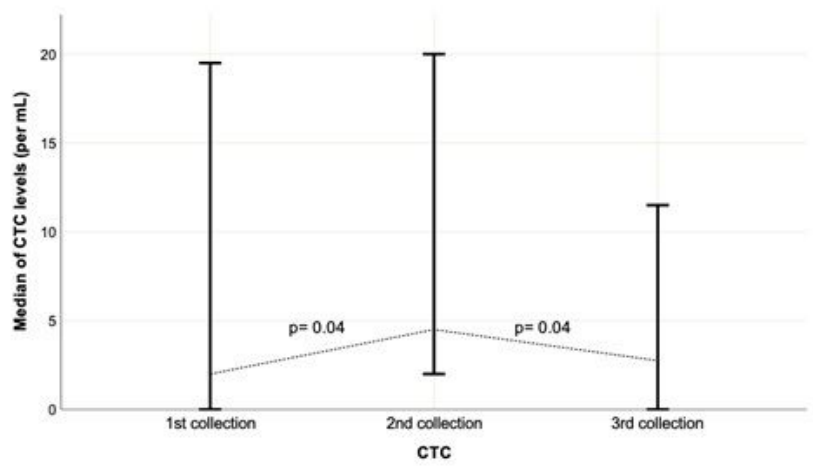

\section{Figure 1}

Median of CTCs/ml in the 3 collections. By the Wilcoxon test, we observed that the CTCs in the whole group increased with a statistically significant difference between the first and the second collection $(p=0.04)$, and between the second and third collection they decreased with a statistically significant difference ( $p$ $=0.04)$. 


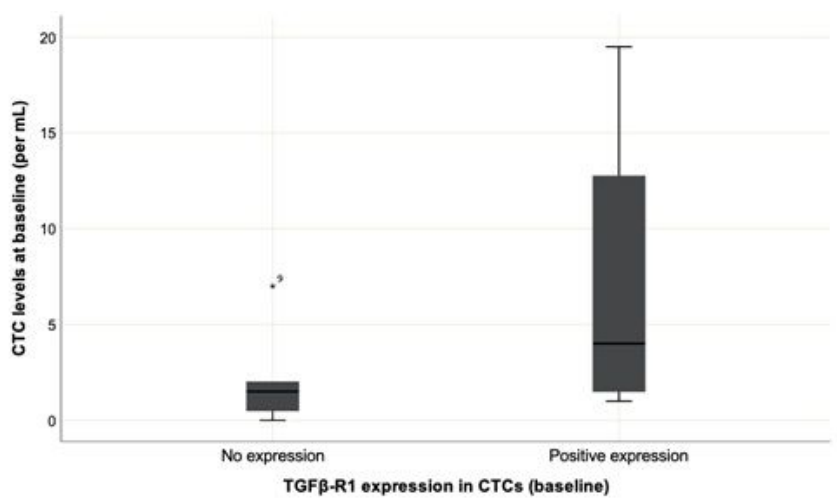

Figure 2

Distribution of CTCs in protein expression of TGF $\beta$-R1 in the first collection. It has no statistical significance $(p=0.09)$. The quantitative distribution of variables was calculated using the Mann-Whitney U test.
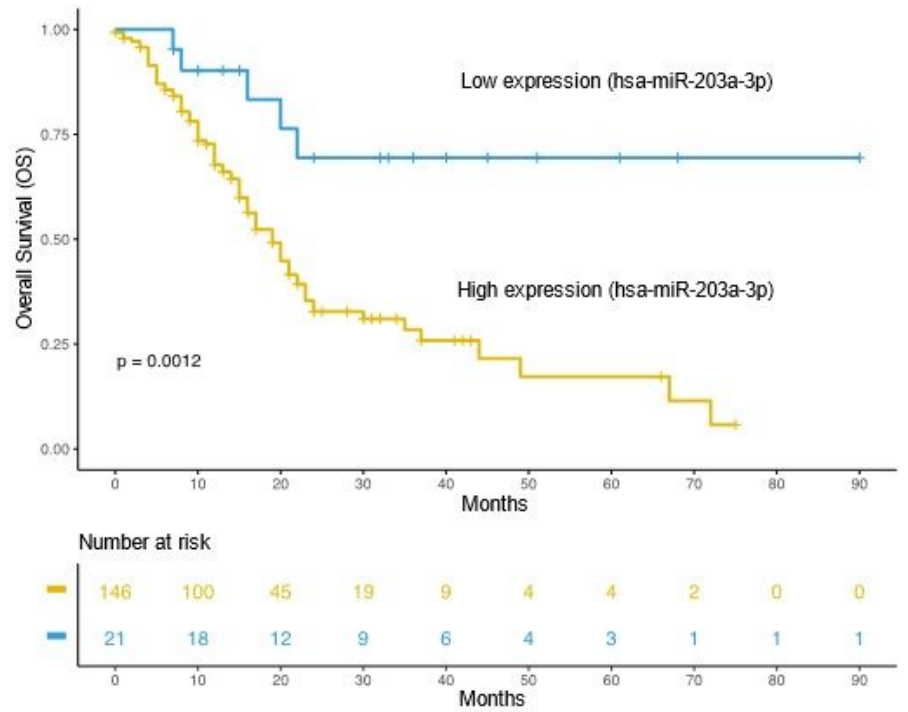

Figure 3

The increased expression of miR-203a-3p is associated with poor overall survival in patients with pancreatic cancer with initial disease stage after analysis with TCGA data. 